\title{
Células de aprendizagem
}

\section{George Max Costa Sarzêdas}

ciep479@gmail.com

CIEP Brizolão 479 - Mario Simão Assaf - Cachoeiras de Macacu -RJ - Brasil.

\section{Resumo}

O projeto em tela consiste basicamente em incorporar ao projeto de Monitoria Supervisionada os alunos de melhores resultados. Estes alunos deverão ser protagonistas do aprendizado de seus pares, àqueles que ao longo do processo demonstram dificuldades inerentes ao aprendizado da disciplina de Matemática.

Os recursos destinados à execução deste projeto serão utilizados em duas frentes. A primeira frente deverá prover ajuda de custo para alunos monitores. Desta forma, o protagonismo deste estudante se fará de maneira a gerar comprometimento e atingimento de suas metas. A segunda frente proverá ferramenta tecnológica, por meio da aquisição e disponibilização de Tablets que servirão como auxílio ao aprendizado da matemática, por meio de inúmeros aplicativos freewares disponíveis hoje, voltados exclusivamente para essa ação.

O monitoramento dos resultados será feito a partir dos resultados obtidos na aplicação e correção dos instrumentos de avaliação externos (SAERJ, SAERJINHO, PROVA BRASIL). Além disto, o monitoramento dos resultados de fluxo na unidade escolar, obtidos ao final de cada bimestre.

O foco não será apenas no resultado, estaremos atentos à capacidade de utilização do aprendizado numa visão mais ampla. $\mathrm{O}$ auxilio dos docentes se dará por meio de oficinas de aprofundamento, onde o objeto do estudo será a prática da matemática e suas aplicações cotidianas.

Para a execução desta proposta o investimento nos próximos 24 meses ficará na ordem de 90 mil reais, envolvendo 40 alunos do ensino Fundamental II e 3 professores. Os resultados esperados são os seguintes:

1) Adesão de alunos monitores ao projeto;

2) Aumento do índice de aprovação para o Ensino Fundamental II para $70 \%$ dos alunos no primeiro ano;

3) Aumento do IDEB e IDERJ em 30\%.

Palavras-chaves: Educação. Tecnologias de ensino. Plano de empreendimento. Monitoria. 


\section{Contexto da escola}

CIEP Brizolão 479 - Mario Simão Assaf, escola pública Estadual - Estado do Rio de Janeiro foi fundada em 1993 e localizada em São Francisco de Assis - Cachoeiras de Macacu / RJ. São 510 alunos divididos entre Ensino Fundamental II ( $6^{\circ}$ ao $9^{\circ}$ Anos Escolares), Ensino Médio Regular ( $1^{\circ}$ ao $3^{\circ}$ Anos Escolares) e Educação de Jovens e Adultos (Fases I, II e III)

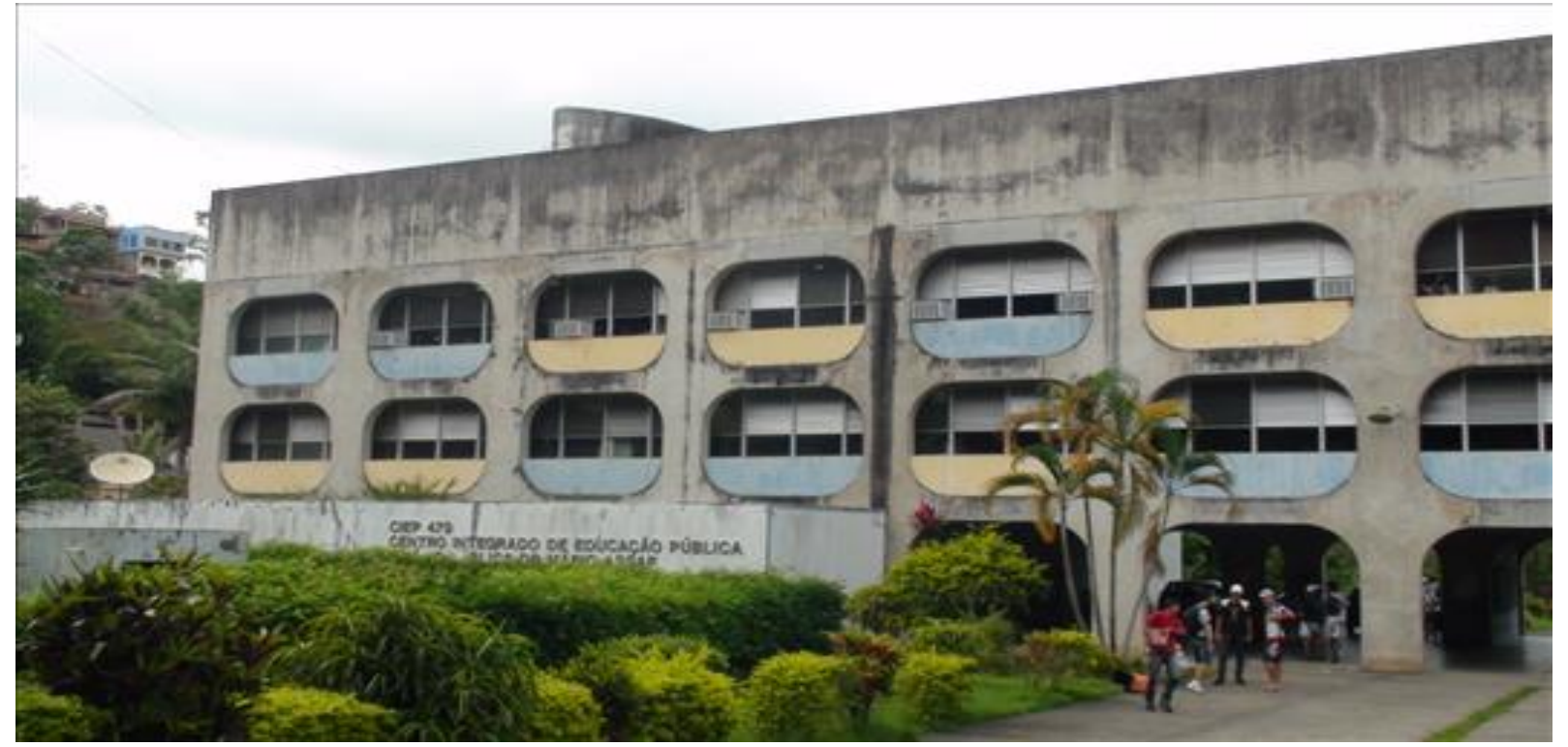

Figura 1: Vista frontal da Unidade Escolar.

Missão: Proporcionar condições adequadas para o desenvolvimento das múltiplas inteligências a partir do reconhecimento dos aspectos cognitivos e não cognitivos inerentes ao processo ensino aprendizagem. Promover 0 entendimento das relações sociais a partir da interação escola $x$ comunidade, valorizando a solidariedade, o respeito, o bem comum e os direitos universais..

Visão: Consolidar o papel da instituição na excelência da formação acadêmica de nossos alunos garantindo assim o ingresso destes à Universidade, à formação profissional, bem como, ao mercado de trabalho.

Localizado na zona urbana do Município de Cachoeiras de Macacu, há 20 anos o Ciep Brizolão 479 - Mario Simão Assaf atende a adolescentes e adultos nas modalidades de Ensino Fundamental II, Ensino Médio Regular e Educação de Jovens e Adultos.

A instituição foi criada para dar continuidade ao Programa Especial de Educação que atendia exclusivamente a Educação Básica, então denominadas $1^{a}$ a $4^{a}$ Séries. Nossa instituição, desde sua origem, esteve na vanguarda do processo ensino aprendizagem, ora como programa especial de educação (horário integral) e agora, com a oferta de projetos ligados às politicas educacionais promovidos pela SEEDUC-RJ e Ministério da Educação (FNDE). Historicamente temos um compromisso com o ingresso dos concluintes nas várias Universidades Públicas e Particulares (via programas - PROUNI, FIES, SISU). Nosso resultado demonstra que esse objetivo vem sendo atingido, mas precisamos manter o foco nesta questão, tendo-a como prioritária. Possuímos uma articulação profícua com as politicas educacionais promovidas pelas várias esferas de gestão (União-Estado-Município). Em grande parte essas articulações estão relacionadas com os Projetos e Programas que são destinados tanto à formação quanto a experiência profissional. O Pronatec, o Renda Melhor Jovem, Jovem aprendiz dos Correios, Jovem aprendiz do Poder Judiciário (MP e TJ), todos programas voltados para a capacitação dos nossos alunos. 
Células de aprendizagem

Nossa sede é própria possui 18 salas e atende 510 alunos em três modalidades de ensino em 02 turnos como segue:

\begin{tabular}{|lll|}
\hline Modalidade & Turno & Quantidade \\
\hline Ensino Fundamental II & Manhã & 231 \\
\hline Ensino Médio Regular & Integral & 166 \\
\hline Ensino Médio EJA - Nova EJA & Noturno & 89 \\
\hline Programa Autonomia & Manhã & 24 \\
\hline
\end{tabular}

Tabela 1: Quadro geral de alunos

A escola possui o seguinte organograma funcional:

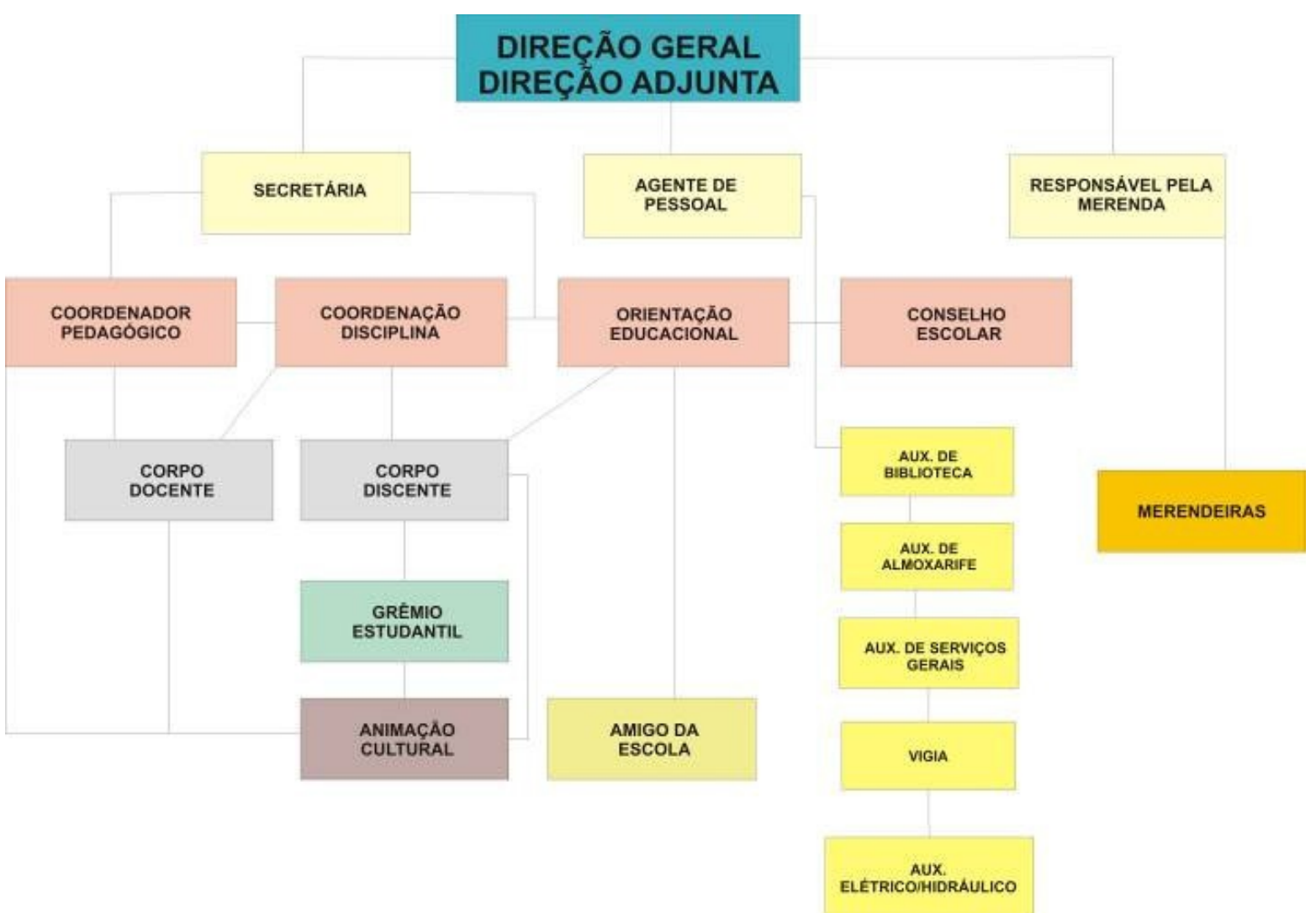

Figura 1: Organograma da Unidade Escolar

A escola possui Merendeiras, porteiro e agente de Limpeza, tanto terceirizados quanto concursados.

\section{Professores}

A escola possui em seu quadro de pessoal:

Diretor Geral (01), Diretor Adjunto (02), Orientador Educacional (01) Secretária (01) Coordenador de Turno (02). 
O quadro de docentes é distribuído da seguinte maneira:

(04) Língua Portuguesa, (04) Matemática, (01) Ciências, (02) Geografia, (04) História, (02) Língua Estrangeira Inglês, (01) Educação Física, (02) Artes, (01) Biologia, (01) Química, (01) Sociologia/Filosofia, (03) Resolução de Problemas Matemáticos, (03) Leitura e Produção Textual.

Todos os docentes possuem Graduação Universitária em suas respectivas disciplinas e esse fato muito contribui para a obtenção dos bons resultados de proficiência dos últimos anos.

A relação destes com os alunos é cordial e altamente produtiva

\section{Alunos}

A escola atende alunos do Ensino Fundamental II (anos finais), assim distribuídos:

\begin{tabular}{|lllll|}
\hline Série/Ano & $6^{\circ}$ Ano & $7^{\circ}$ Ano & $8^{\circ}$ Ano & $9^{\circ}$ Ano \\
\hline $\mathrm{N}^{\circ}$ de Alunos & 54 & 61 & 60 & 56 \\
\hline
\end{tabular}

A escola atende alunos do Ensino Médio Regular, assim distribuídos:

\begin{tabular}{|llll|}
\hline Série/Ano & $1^{\circ}$ Ano & $2^{\circ}$ Ano & $3^{\circ}$ Ano \\
\hline $\mathbf{N}^{\circ}$ de Alunos & 65 & 55 & 46 \\
\hline
\end{tabular}

A escola atende alunos da Modalidade de Jovens e Adultos, assim distribuídos:

\begin{tabular}{|llll|}
\hline Série/Ano & Fase I - M01 & Fase I - M02 & Fase III \\
\hline $\mathrm{N}^{0}$ de Alunos & 28 & 24 & 37 \\
\hline
\end{tabular}

A escola atende alunos do Programa Autonomia, assim distribuídos:

\begin{tabular}{|ll|}
\hline Série/Ano & PAEF - M04 \\
\hline $\mathrm{N}^{0}$ de Alunos & $\mathbf{2 4}$ \\
\hline
\end{tabular}

Realizamos atendimento especial especializado (Deficiência Física) a apenas 01 aluno, matriculado na turma de Programa Autonomia.

\section{Características mais marcantes do local onde a escola se insere}

Localizada a $1 \mathrm{~km}$ do centro, a escola esta colocada numa região extremamente bucólica, às margens do Rio Macacu. A escola divide espaço com um campo de futebol muito utilizado pela comunidade tanto nos dias úteis quanto nos finais de semana. As dependências comuns localizadas na área externa, (mesa de tênis concretadas no nosso jardim, somada as quadras de vôlei) promovem uma sensação real de pertencimento da escola à comunidade em que ela esta inserida, haja visto, o fato de que são utilizadas nos finais de semana. Por esta razão embora tenhamos 20 anos de existência o prédio não apresenta nenhum sinal de depredação, pichação ou similares.

Desde a última avaliação de larga escala (Prova Brasil), a escola alavancou a nota IDEB para o patamar de 4,3, já conquistando a meta planejada para esse ano. Numa clara demonstração de confiança, os índices de transferência ao final do Ensino Fundamental II foram erradicados. Hoje para cada aluno que cursa essa modalidade temos um novo aluno na modalidade de Ensino Médio Regular.

\section{Identificação do problema ou da oportunidade}

Desde a instituição do Índice de desenvolvimento da Educação Básica, a partir do compromisso "Todos pela Educação", que mobilizou a sociedade civil, a União, os Estados e os Municípios, demos início ao acompanhamento das metas estabelecidas e os resultados aferidos bienalmente.

Diante da análise dos nossos resultados observamos uma fragilidade relacionada com as habilidades e competências na disciplina de Matemática. Inicialmente tomamos por providência instituir, obrigatoriamente aos alunos ingressantes do $6^{\circ}$ ano do Ensino Fundamental II, uma avaliação diagnóstica que nos permitisse 


\section{Células de aprendizagem}

com segurança, estabelecer o nivelamento da proficiência desses novos alunos, levando-se em conta as habilidades e competências presentes na avaliação Oficial para $05^{\circ}$ Ano Escolar. $O$ instrumento escolhido para nos auxiliar nesse balizamento foi a Prova Brasil, disponibilizada no site do INEP.

Os resultados (2010) apontavam a matemática como o foco do problema, mais de $60 \%$ das habilidades previstas para a série não foram dominados pela maioria dos alunos. 0 resultado obtido em língua portuguesa não foi muito melhor que o de matemática, porém mais promissor, haja vista que os descritores/habilidades de pior resultado não foram o suficiente para atrapalhar o trabalho proposto.

No período que se seguiu (2011), os resultados não apresentaram mudanças significativas. Contudo, a avaliação diagnóstica nos possibilitou encontrar os alunos que apresentavam melhor resultados se comparados à maioria da turma e, por essa razão poderiam ser acelerados com propostas de ensino diferenciadas, alvo de nossa proposta.

A partir deste ponto estabelecemos duas frentes de trabalho bem claras. A primeira consistia em oferecer através do Programa Mais Educação (FNDE-MEC), oficinas de letramento (Português e Matemática) no contra turno, capazes de corrigir as discrepâncias encontradas no diagnóstico (implementada em 2011). A segunda frente estabelecia um contexto de aceleração de estudos a partir da formação de grupos de aceleração (implementada em 2012).

Nesse momento (2012), e sem o apelo do baixo rendimento, não conseguimos consolidar a proposta frente ao fato da inconstância na frequência dos alunos aos encontros estabelecidos por eles mesmos. Outro fator preponderante para não termos obtido sucesso foi o número de profissionais que poderiam agir diretamente com esse projeto na Unidade Escolar, de forma que os grupos ganhassem folego e produzissem o esperado. Vale ressaltar que essa experiência foi oferecida a principio para todos os anos escolares.

Em 2013, com a ampliação da jornada de 25 para 29 tempos semanais no Ensino Fundamental II (matemática e português receberam um incremento de 02 aulas semanais a partir da criação das disciplinas de Resolução de Problemas Matemáticos e Leitura e Produção Textual, respectivamente) redimensionar professores, currículo, matrizes de referência foi fundamental para a mudança no cenário que tínhamos conhecimento.

Vale ressaltar que o projeto de análise diagnóstica, realizada na chegada dos alunos à modalidade de Ensino Fundamental II teve início em 2010 e, agora em 2013, encerraremos um ciclo por completo $\left(6^{\circ}, 7^{\circ}, 8^{\circ}\right.$ e $9^{\circ}$ anos escolares). A leitura e confiabilidade desse resultado são fundamentais para a checagem do que acertamos e erramos ao longo desse período.

Mesmo diante das dificuldades encontradas colhemos resultados interessantes, mas outros diagnósticos precisavam ser feitos. Não tínhamos grande conhecimento de gestão, bem como, as informações existentes não possuíam a confiabilidade e a consistência para subsidiar uma discussão tão necessária.

Os ventos mudaram, uma nova administração (SEEDUC-RJ) estabelece um novo cenário a nossas gestões. 0 grande salto se fez. Avaliações pontuais acompanhadas de análises por habilidades e competências, sistema mais confiável e preparado para elaboração de relatórios de análise de frequência e proficiência, enfim, um modelo de gestão (PDCA).

Novos formatos de discussão dos velhos problemas (braisnstorming, Benchmarketing, Matriz GUT, Matriz SWOT), novas respostas, mais participação. Eis que surge uma nova perspectiva, uma nova ordem gerencial.

Diante dessa nova ordem, em sequência apresento alguns dos indicadores coletados nos últimos dois anos, demonstrando o cerne de nossa limitação e a posteriori a proposta para mudarmos esse cenário.

\section{IDEB da Unidade Escolar}

\begin{tabular}{|c|c|c|c|c|c|c|c|c|c|}
\hline & \multicolumn{4}{|c|}{ Ideb Observado } & \multicolumn{5}{|c|}{ Metas Projetadlas } \\
\hline Escola * & $2005 *$ & $2007 \div$ & $2009 \div$ & $2011 *$ & $2007 \div$ & $2009 \div$ & $2011 \div$ & $2013 *$ & $2015 \div$ \\
\hline CIEP BRIZOLAO 479 DOUTOR MARIO SIMAO ASSAF & 3.2 & 3.0 & 2.9 & 4.3 & 3.3 & 3.4 & 3.7 & 4.1 & 4.5 \\
\hline
\end{tabular}

Fonte INEP/MEC 


\section{Resultados do SAERJINHO - Consolidado do $1^{\circ}$ Semestre 2012 em comparação ao mesmo}

\section{período 2013}

\begin{tabular}{|c|c|}
\hline \multicolumn{2}{|c|}{$9^{\circ}$ anOS - 2012} \\
\hline 901 - MAT & 902 - MAT \\
\hline BAIXO & BAIXO \\
\hline $33 \%$ & $24 \%$ \\
\hline INTER & INTER \\
\hline $60 \%$ & $56 \%$ \\
\hline ADEQUADO & ADEQUADO \\
\hline $7 \%$ & $20 \%$ \\
\hline AVANÇADO & AVANÇADO \\
\hline 0\% & $0 \%$ \\
\hline
\end{tabular}

\begin{tabular}{|c|c|}
\hline \multicolumn{2}{|c|}{ 9o Anos 2013} \\
\hline 901 - MAT & 902 - MAT \\
\hline BAIXO & BAIXO \\
\hline $\mathbf{1 7 , 9}$ & 13,8 \\
\hline INTER & INTER \\
\hline $\mathbf{4 6 , 4}$ & $\mathbf{6 2 , 1}$ \\
\hline ADEQUADO & ADEQUADO \\
\hline $\mathbf{2 8 , 6}$ & $\mathbf{2 4 , 1}$ \\
\hline AVANÇADO & AVANÇADO \\
\hline 0,0 & 0,0 \\
\hline
\end{tabular}

\section{Caracterização do produto/serviço e/ou processo \\ Descrição do Projeto}

O Projeto consiste na criação de Células de Aprendizagem (máximo de 05 alunos para cada aluno tutor) a partir da indicação de alunos tutores pelos professores de Matemática.

Os alunos tutores se tornam responsáveis pelo aprendizado daqueles sob sua tutoria, buscando a melhora dos resultados de proficiência destes.

Os tutores receberão a titulo de ajuda de custo um valor simbólico de $\mathrm{R} \$ 50,00$ (cinquenta reais) mês, que poderão ser acrescidos de bonificação extra de mesmo valor se os seus tutelados obtiverem crescimento de ao menos $30 \%$ do obtido no período anterior.

Este projeto fundamenta-se a partir da análise dos indicadores de proficiência (SAERJINHO, SAERJ e Prova Brasil) e, em especial na disciplina de matemática, haja vista os baixos resultados obtidos. Trata-se de uma proposta clara para aumentar o estudo da disciplina de matemática de maneira a revertermos os resultados abaixo do esperado.

Este projeto baseia-se numa experiência bem sucedida do Colégio Santo Agostinho, situado na cidade do Rio de Janeiro e adaptada à nossa realidade após incessantes discussões no ambiente da escola a partir da chegada de um profissional que leciona atualmente em ambas as instituições.

\section{Passo a Passo}

\section{$1^{0}$ Passo}

A primeira etapa do projeto consiste em prover um diagnóstico das Habilidades e Competências na disciplina de Matemática em todas as turmas e anos escolares compreendidos pelo Ensino Fundamental II em nossa escola e, não apenas $06^{\circ}$ ano como fazemos atualmente.

\section{$2^{\circ}$ Passo}

A segunda etapa ocorre simultaneamente à primeira, uma vez que também avaliaremos os alunos com melhor proficiência convidando-os após análise dos resultados de participarem do projeto.

\section{$3^{\circ}$ Passo}

A terceira etapa consiste em capacitar através das oficinas (Mais Educação e Reforço Escolar) os alunos selecionados de maneira que a proposta seja padronizada, permitindo que avaliemos o desempenho ao final de cada etapa (necessária para o cálculo do bônus, caso haja). 


\section{Células de aprendizagem}

\section{$4^{0}$ Passo}

A quarta etapa é apresentar o resultado das avaliações regulares (Bimestrais) junto com os resultados obtidos pelos alunos engajados na proposta, comparando-os (aluno do projeto $X$ aluno). Dessa forma almejamos que 0 aluno interprete esse momento como um reconhecimento positivo do seu esforço e do seu aprendizado, bem como, servir de motivação e exemplo para àqueles que não participam diretamente, fazêlo.

\section{$5^{\circ}$ Passo - (Expectativas)}

A expectativa deste empreendimento institui que numa escala de conquistas ao final de 01 (um) ano 0 desempenho acadêmico de $70 \%$ dos alunos esteja na faixa denominada pelo sistema de avaliação IDEB/SAERJ como Adequada (entre 50\% e 75\%) nas avaliações de larga escala (Prova Brasil-SAERJ) para esta disciplina.

A manutenção deste projeto num ciclo completo (4 anos) pretenderá alcançar a margem de $100 \%$ de alunos distribuídos em $60 \%$ no nível denominado Adequado e $40 \%$ no nível denominado Avançado (entre $76 \%$ e $100 \%)$.

\section{Principais Custos}

Os custos diretos estão relacionados com a remuneração dos tutores (contrapartida) e os materiais necessários ao desenvolvimento das atividades (Xérox, Papel, Caderno, Caneta, Lápis, Borracha, Régua, Cola, Papel Milimetrado, Tesoura, entre outros - Custeio).

Levando-se em consideração a criação de 04 Células de Aprendizagem por turma na disciplina de Matemática nas turmas de Ensino Fundamental II ( $6^{\circ}$ ao $9^{\circ}$ ano), chegamos a um total de 32 (trinta e duas) células. O Material necessário deverá ser adquirido em duas compras (01 por semestre) e estarão previstos nas despesas de custeio.

Instituiremos o pagamento de bônus para cada tutor que apresente resultado acima de $30 \%$, calculados a partir da média de todos os seus tutelados. $O$ valor do Bônus é o mesmo valor pago como ajuda de custo e não pode ultrapassar a $50 \%$ do número de células criadas. Os critérios para escolha dos que receberão 0 Bônus será sempre do maior para o menor resultado respeitando o percentual de $50 \%$ das células criadas.

Finalizando os investimentos pretendemos adquirir equipamentos (tablets - 10' com sistema android) que serão utilizados pelos tutores nas atividades propostas, tornando as aulas mais atrativas e conectadas com a "realidade virtual" dos alunos.

A seleção dos aplicativos será feita pelos docentes responsáveis pelo projeto e utilizados pelos tutores após uma prévia demonstração e conexão estabelecida pelo professor da turma. A priori o interesse é que as atividades propostas estejam conectadas com as habilidades que apresentam menor desempenho.

\section{Investimento Pré-operacional}

Caso esse projeto venha a obter financiamento para sua existência estimo que o investimento Préoperacional, resida no financiamento de 300 cartilhas explicativas para distribuição aos responsáveis tanto dos tutores quanto dos tutelados, descrevendo de maneira clara e concisa, todas as etapas e comprometimentos dos envolvidos no processo.

Desta maneira promoveremos nossa estratégia de Marketing, bem como o alinhamento e aceite da comunidade escolar quanto ao projeto proposto. 


\section{Estratégia de implementação}

\section{Análise FOFA}

\section{Forças}

Não possuímos carência na disciplina de Matemática nas turmas que serão atendidas;

O projeto funciona em caráter experimental no $2^{\circ}$ Semestre 2013 (células de aprendizagem, menos o uso dos Tablets);

No primeiro momento de avaliação realizamos um aumento real de $40 \%$ no número de aprovações para 0 período;

Apoio da Comunidade Escolar

\section{Oportunidades}

> Com a introdução dos Tablets, esperamos alcançar 100\% dos alunos matriculados nas séries atendidas pelas Células de Aprendizagem;

Tornar atraentes as aulas de matemática, através do uso de recursos tecnológicos e aplicativos que auxiliem no seu aprendizado;

> Ampliar a permanência do aluno na escola a partir da oferta de outras atividades ligadas ao uso de outras tecnologias e propósitos (Oficina de Teatro, Oficinas Esportivas, Oficinas de Música e Oficinas de Xadrez);

Aproveitar a motivação dos alunos que conquistaram bons resultados, para divulgar e convidar outros a participarem da atividade.

\section{Fraquezas}

Dispor de recursos específicos para manutenção e substituição das peças (Tablets) obsoletas e defeituosas, de maneira que possamos manter cada aluno utilizando um equipamento.

\section{Ameaças}

Não dispor de recursos específicos para manutenção e substituição das peças (Tablets) obsoletas e defeituosas, de maneira que possamos manter cada aluno utilizando um equipamento.

\begin{tabular}{|c|c|c|}
\hline Objetivos & Metas & Estratégias \\
\hline $\begin{array}{l}\text { Aumentar a Taxa } \\
\text { de Aprovação nas } \\
\text { turmas de } 6^{\circ} \text { ao } 9^{\circ} \\
\text { ano na disciplina de } \\
\text { Matemática }\end{array}$ & $\begin{array}{l}\text { Elevar os índices de } \\
\text { aprovação na disciplina de } \\
\text { Matemática nas turmas do } 6^{\circ} \\
\text { ao } 9^{\circ} \text { ano do patamar atual } \\
\text { para até o final do projeto ( } 24 \\
\text { meses) }\end{array}$ & $\begin{array}{l}\text { - Reforçar a estrutura existente nas células de aprendizagem a } \\
\text { - } \quad \text { Aumentir da aquisição de recursos tecnológicos (Tablets); } \\
\text { responsáveis pelas células de aprendizagem; } \\
\text { - } \quad \text { Oferecer outros horários (contra turno) para a realização das } \\
\text { atividades relacionadas com a aplicação e uso dos aplicativos } \\
\text { escolhido para uso nos Tablets. }\end{array}$ \\
\hline
\end{tabular}

\begin{tabular}{|lll|}
\hline O que vou precisar & Descrição & Como obter \\
\hline Tablets para os alunos & $\begin{array}{l}\text { A aquisição deste equipamento é } \\
\text { fundamental para a ampliação do } \\
\text { interesse dos alunos nas atividades } \\
\text { propostas pelos colegas (responsáveis } \\
\text { pelas células de aprendizagem), bem } \\
\text { como, da participação em horários }\end{array}$ & $\begin{array}{l}\text { Recursos obtidos via Edital Projetos Inovadores, verba } \\
\text { prevista para material permanente (Capital). }\end{array}$ \\
\hline
\end{tabular}




\section{Indicadores}

Utilizaremos como indicadores nas séries avaliadas pelo SAERJINHO ( $9^{\circ}$ ano do EFII) os resultados expressos no site do CAED-UFJF (www.saerjinho.caedufjf.net), quanto ao resultado mensurado para as habilidades avaliadas em cada bimestre (ID).

Nos demais anos escolares utilizaremos a seguinte fórmula ao final de cada período bimestral:

$\mathrm{N}^{0}$ de Aprovados - $\mathrm{N}^{0}$ de Reprovados X 100

$\mathrm{N}^{0}$ de alunos Matriculados na Turma/Série

\section{Marketing e comunicação}

Por se tratar da ampliação e incremento das atividades desenvolvidas no projeto iniciado no ano de 2013 , estabelecemos como inicial e abrangente a criação de uma cartilha contendo todos os resultados, indicadores e propósitos que levaram a existência da proposta.

Aproveitaremos para ampliar o alcance do projeto àqueles que não foram atingidos nesse primeiro momento. Desta forma, cumpriremos com nosso primeiro e mais ambicioso objetivo que é atingir $100 \%$ dos alunos de cada turma do Ensino Fundamental II.

Escolheremos uma data para a apresentação do projeto, suas metas futuras e dos resultados preliminares (2013) aos Pais e Responsáveis, de maneira que a leitura e o entendimento da cartilha sejam amplamente absorvidos pela comunidade escolar.

Acreditamos piamente que essa iniciativa (proposta) alavancará os resultados, permitindo o alcance das metas dentro do período planejado.

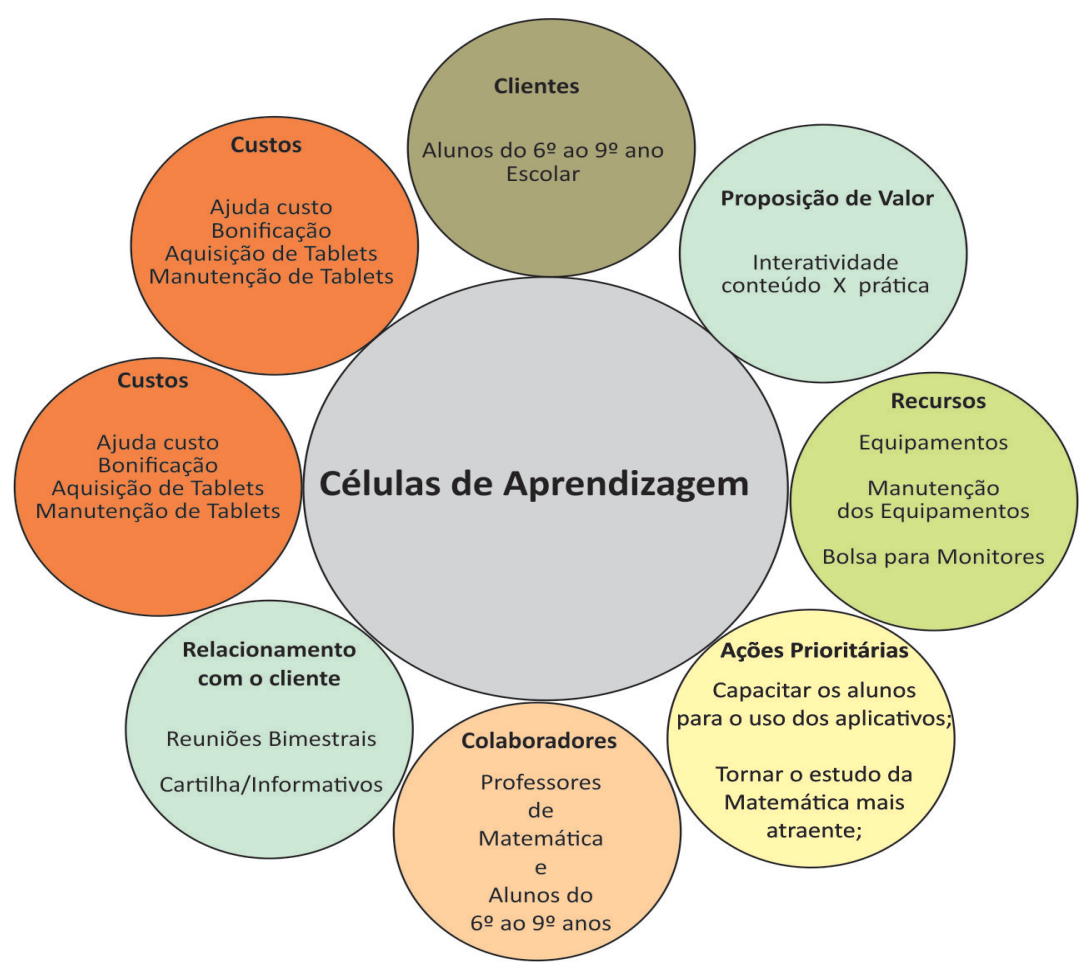

Figura 2: Esquema de Sistema em Células 


\section{Organização e gerência do empreendimento}

\section{Equipe de Gestão}

Aqui apresentaremos os membros da equipe pedagógica e gestora que participarão ativamente de todos os processos relacionados com o planejamento das ações pedagógicas, aquisição de equipamentos, tabulação das informações, prestação de contas dos recursos utilizados e demais atribuições inerentes ao processo.

\begin{tabular}{|c|c|c|c|}
\hline NOME & FUNÇÃO & FORMAÇÃO/EXPERIÊNCIA & PRINCIPAIS ATIVIDADES NO PROJETO \\
\hline George & Diretor Geral & $\begin{array}{l}\text { MBA em Gestão Empreendedora } \\
\text { - É gestor da Unidade Escolar há } \\
12 \text { anos e Professor de Educação } \\
\text { Física }\end{array}$ & $\begin{array}{l}\text { Gestor responsável pela cotação, aquisição, } \\
\text { pagamentos e prestação de contas dos } \\
\text { Recursos Financeiros elencados para a } \\
\text { execução das atividades deste projeto. }\end{array}$ \\
\hline Emilio & Prof. Matemática & $\begin{array}{l}\text { Pós Graduação em Análise de } \\
\text { Sistemas, Graduado em } \\
\text { Matemática, Professor de } \\
\text { Informática do Colégio Santo } \\
\text { Agostinho - RJ }\end{array}$ & $\begin{array}{l}\text { Junto com a Direção foi o mentor do Projeto. } \\
\text { Será o responsável direto pela escolha, } \\
\text { capacitação e formação dos alunos indicados } \\
\text { pelos seus pares da disciplina de Matemática. }\end{array}$ \\
\hline Maicon & Prof. Matemática & Graduado em Matemática & $\begin{array}{l}\text { Ficará responsável pelo acompanhamento, } \\
\text { coleta e tabulação dos resultados de } \\
\text { aprovação. Realizará a análise destes dados } \\
\text { e transmitirá para os demais professores e } \\
\text { colaboradores. }\end{array}$ \\
\hline
\end{tabular}

Tabela 2: Equipe de Gestão

\section{Processos}

\begin{tabular}{|c|c|c|}
\hline Processos & Colaborador & Perfil \\
\hline \multirow[t]{3}{*}{$\begin{array}{l}\text { Capacitação dos Monitores } \\
\text { e professores no uso dos } \\
\text { aplicativos para Tablet }\end{array}$} & Emilio Ventura da Silva & $\begin{array}{l}\text { Conhecimento: Formado há } 20 \text { anos e atuando na rede } \\
\text { particular. Já foi dono de escola por } 10 \text { anos. Consultor da } \\
\text { DATAMEC . Foi responsável pela implantação do sistema de } \\
\text { leitura e automação da leitura dos Cartões de Loteria. }\end{array}$ \\
\hline & & $\begin{array}{l}\text { Habilidade: Profundo conhecedor das várias tecnologias } \\
\text { assistidas ou não, ora disponíveis e que se pretende } \\
\text { disponibilizar aos alunos durante a implementação deste } \\
\text { projeto. }\end{array}$ \\
\hline & & $\begin{array}{l}\text { Atitude: Profissional altamente dedicado à causa da } \\
\text { educação. Hoje reconhecido pelos colegas e alunos como } \\
\text { um professor disciplinador, mas eficiente. Possui os } \\
\text { melhores resultados de proficiência na Unidade Escolar. } \\
\text { Empático e Dedicado. }\end{array}$ \\
\hline \multirow[t]{2}{*}{$\begin{array}{lll}\begin{array}{l}\text { Seleção } \\
\text { Monitores }\end{array} & \text { Alunos } \\
\end{array}$} & Profa. Carmem Verônica & $\begin{array}{l}\text { Conhecimento: Atua como docente a mais de } 20 \text { anos. Na } \\
\text { disciplina de Matemática nos últimos } 10 \text { e como docente } \\
\text { nesta Unidade Escolar há } 16 \text { anos. }\end{array}$ \\
\hline & & Habilidade: Extremamente expansiva e desinibida possui \\
\hline
\end{tabular}




\begin{tabular}{|c|c|}
\hline & $\begin{array}{l}\text { tráfego com todos os alunos e demais docentes da Unidade } \\
\text { Escolar. Como atua nas séries iniciais do } 2^{\circ} \text { Ciclo do Ensino } \\
\text { Fundamental, fica responsável pela escolha e condução do } \\
\text { projeto nas turmas cuja avaliação diagnóstica aponta os } \\
\text { alunos de maior defasagem de habilidades e competências. } \\
\text { Atitude: Pessoa extremamente flexível e capaz. Empática e } \\
\text { de excelente trânsito junto ao corpo discente. }\end{array}$ \\
\hline $\begin{array}{lrr}\text { Coleta, Tabulação } & \text { e } & \text { Prof. Maicon Saldanha } \\
\text { Distribuição } & \text { dos } & \\
\text { Resultados } & & \end{array}$ & $\begin{array}{l}\text { Conhecimento: Recém contratado pela SEEDUC concluiu a } \\
\text { Graduação a mais de } 10 \text { anos. Possui experiência na coleta } \\
\text { e tabulação de informação. Auxilia a Unidade Escolar na } \\
\text { tarefa de mensurarmos os resultados obtidos após a } \\
\text { aplicação das Avaliações Institucionais (SAERJINHO). } \\
\text { Habilidade: Profundo conhecedor do trabalho estatístico } \\
\text { necessário ao controle e aferição dos resultados } \\
\text { desenvolvidos pelo projeto ao longo de sua aplicação. } \\
\text { Atitude: Profissional envolvido com a Unidade Escolar seus } \\
\text { objetivos e Metas. Mostra-se aberto a novas propostas e } \\
\text { principalmente em colaborar com elas. }\end{array}$ \\
\hline $\begin{array}{l}\text { Confecção de Informativos } \\
\text { e Atualização dos dor George Max } \\
\text { resultados à comunidade } \\
\text { escolar }\end{array}$ & $\begin{array}{l}\text { Conhecimento: MBA em Gestão Empreendedora, possui rara } \\
\text { Habilidade nas várias ferramentas de edição de imagens e } \\
\text { textos (Corel, Photo Paint, Publisher e similares). } \\
\text { Habilidade: Confecção de cartazes e manuais já utilizados } \\
\text { pela Unidade Escolar. Responsável pela diagramação dos } \\
\text { mais variados instrumentos presentes nas rotinas escolares } \\
\text { como Ficha de Matricula, Controle de Ocorrências } \\
\text { Disciplinares e Pedagógicas e etc. } \\
\text { Atitude: Autonomia, Habilidade, Agilidade e Organização. }\end{array}$ \\
\hline
\end{tabular}

Tabela 3: Quadro de processos

\section{Plano financeiro}

\section{Investimento (despesa de capital)}

\begin{tabular}{|c|c|c|}
\hline \multicolumn{3}{|c|}{ Investimentos (despesas de capital) } \\
\hline Item & Ano1 & Ano2 \\
\hline Obras e infraestrutura & 0,00 & 0,00 \\
\hline \multicolumn{3}{|l|}{ Obras } \\
\hline \multicolumn{3}{|l|}{ Instalações } \\
\hline Material permanente & $20.970,00$ & 0,00 \\
\hline Equipamentos & $20.970,00$ & \\
\hline \multicolumn{3}{|l|}{ Computadores } \\
\hline Total & $20.970,00$ & 0,00 \\
\hline
\end{tabular}

\section{Detalhamento}

Aquisição de Tablet Samsung Galaxy Tab 3 com Tela 7" SM-T2100 com 8GB, Processador Dual Core de 1.2GHz, Câmera 3MP, Wi-Fi, AGPS e Android 4.1 
Investimento (despesa de custeio)

\begin{tabular}{|c|c|c|}
\hline \multicolumn{3}{|l|}{ Projeção das Despesas Correntes } \\
\hline Material de Consumo & Total ANO 1 & Total ANO 2 \\
\hline Papel A4 & 1680 & 1764 \\
\hline Lápis $2 b$ & 15 & 15,3 \\
\hline Borracha & 60 & 12,42 \\
\hline Régua & 50 & 600 \\
\hline Cola & 70 & 70 \\
\hline Xerox & 1440 & 1468,8 \\
\hline Cartolina & 288 & 73,4 \\
\hline Papel Milimetrado & 62 & 62 \\
\hline Transferidor & 35 & 420 \\
\hline Esquadro & 35 & 420 \\
\hline Total & 3735 & 4905,92 \\
\hline Serviços de Terceiros & Total ANO 1 & Total ANO 2 \\
\hline Ajuda de Custo & 19200 & 19200 \\
\hline Bônus & 9600 & 9600 \\
\hline Total & 28800 & 28800 \\
\hline Total das Despesas Correntes & 32535 & 33705,92 \\
\hline
\end{tabular}

\section{Detalhamento}

Papel A4 - 10 Resmas por mês de maneira a subsidiar a duplicação de atividades que serão utilizadas como atividades programadas nas 08 turmas atendidas pelo projeto;

Lápis $2 \mathrm{~b}$ - 5 caixas para atendimento dos alunos das 08 turmas atendidas pelo projeto;

Borracha - 6 caixas para atendimento dos alunos das 08 turmas atendidas pelo projeto;

Régua - 50 Unidades para atendimento dos alunos das 08 turmas atendidas pelo projeto;

Cola - 5 caixas para atendimento dos alunos das 08 turmas atendidas pelo projeto;

Xérox - 1000 cópias por mês para atendimento dos alunos das 08 turmas atendidas pelo projeto;

Cartolina - 5 pacotes com 100 Unidades para atendimento dos alunos das 08 turmas atendidas pelo projeto;

Papel Milimetrado - 10 pacotes contendo 10 unidades (blocos de 50 folhas) para atendimento dos alunos das 08 turmas atendidas pelo projeto;

Transferidor - 50 Unidades para atendimento dos alunos das 08 turmas atendidas pelo projeto;

Esquadro - 50 Unidades para atendimento dos alunos das 08 turmas atendidas pelo projeto; 


\section{Células de aprendizagem}

Ajuda de Custo - Recurso destinado ao fomento das diversas atividades de formação e acompanhamento realizados pelos Monitores responsáveis pelas Células de Aprendizagem

Bônus - Recurso destinado àqueles que atingirem $30 \%$ ou mais além da meta estabelecida para cada Célula de Aprendizagem. Este valor não ultrapassará $50 \%$ das células existentes e será distribuído sempre do maior avanço mensurado para o menor;

\section{Despesas Administrativas e de Pessoal}

*Valor utilizado como contrapartida

\begin{tabular}{|c|c|c|}
\hline \multicolumn{3}{|c|}{ Projeção das Despesas Administrativas e de Pessoal } \\
\hline Administrativas & Total ANO 1 & Total ANO 2 \\
\hline Energia Elétrica & 2160 & 2322 \\
\hline Marketing - Cartilha & 900 & \\
\hline Total & 3060 & 2322 \\
\hline Pessoal & Total ANO 1 & Total ANO 2 \\
\hline Diretor Geral & 4251 & 4527,315 \\
\hline Prof. DOC I - Matemática EFII (I) & 10882,56 & 11644,3392 \\
\hline Prof. DOC I - Matemática EFII (II) & 10882,56 & 11644,3392 \\
\hline Prof. DOC I - Matemática EFII (III) & 5441,28 & 5822,1696 \\
\hline Total & 31457,4 & 33638,163 \\
\hline Total das Despesas Correntes & 34517,4 & 35960,163 \\
\hline
\end{tabular}

\section{Despesas Administrativas e de Pessoal}

\begin{tabular}{|c|c|c|c|}
\hline \multicolumn{3}{|l|}{ Cálculo da Necessidade de Recursos } & \multirow[b]{2}{*}{ TOTAL } \\
\hline Item & ANO 1 & ANO 2 & \\
\hline I. Total das Despesas Correntes & $32.535,00$ & $33.705,92$ & $66.240,92$ \\
\hline Material de Consumo & $3.735,00$ & $4.905,92$ & $8.640,92$ \\
\hline Serviços de Terceiros & $28.800,00$ & $28.800,00$ & $57.600,00$ \\
\hline II. Total de Despesas Administrativas & $3.060,00$ & $2.322,00$ & $5.382,00$ \\
\hline III. Total de Despesas com Pessoal & $31.457,40$ & $33.638,16$ & $65.095,56$ \\
\hline IV. Total de Despesas de Capital (investimentos) & $20.970,00$ & 0,00 & $20.970,00$ \\
\hline Necessidade de Recursos (I+II+III+IV) & $88.022,40$ & $69.666,08$ & $157.688,48$ \\
\hline Recursos do Edital & $53.505,00$ & $33.705,92$ & $87.210,92$ \\
\hline Recursos da Organização (contrapartida) & $34.517,40$ & $35.960,16$ & $70.477,56$ \\
\hline
\end{tabular}

